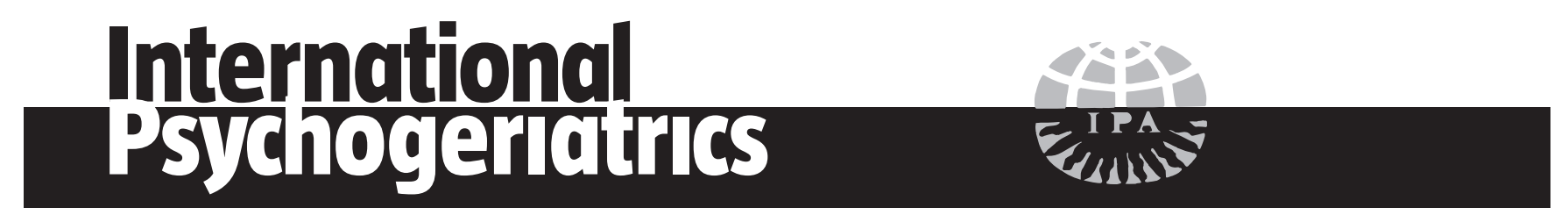

\section{Scope and contributions}

International Psychogeriatrics is written by and for those doing clinical, teaching, and research work with older people. It is the official journal of the International Psychogeriatric Association (IPA) and is published by Cambridge University Press, Cambridge, UK. Although it is primarily concerned with psychogeriatrics, the journal welcomes contributions from all concerned with the field of mental health and aging. Original research papers are particularly sought.

Contributions include original research articles, case reports, reviews of the literature, book reviews, letters to the editor, and editorials. Apart from editorials and book reviews, which are commissioned, contributions to International Psychogeriatrics are spontaneously written and submitted by authors. Papers are reviewed by two expert reviewers selected by the Editor-in-Chief. At present, about half of the papers submitted are accepted for publication The journal's Science Citation Index Impact Factor (2007) is 2.207. Submission of a paper implies that it is neither under consideration for publication elsewhere, nor previously published in English. Manuscripts must be formatted double-spaced with ample margins on all sides and the pages should be numbered. International Psychogeriatrics uses the spelling of American English. Manuscripts written by those whose primary language is not English should be edited carefully for language prior to submission. The journal has a Language Assistance Panel consisting of both native English speakers willing to check mauscripts for style prior to submission, and bilingual experts willing to assist with the translation of manuscripts into English. Further details including contact information for individual panel members can be found at both the journal and IPA websites (journals.cambridge.org/ipg and www.ipa-online.org).

The instructions for contributors are published in the first issue of International Psychogeriatrics each year. An up-to-date version can be found at the International Psychogeriatrics website journals.cambridge. org/IPG. Please read these instructions carefully before submitting articles. Articles that are not prepared in accordance with these guidelines will be returned to authors.

Send the electronic manuscript by email (or, if that is not possible, on computer disk) to the office of the editor-in-chief:

Professor David Ames, Editor-in-Chief, International Psychogeriatrics Normanby House,

St George's Hospital,

283 Cotham Rd.,

Kew,Victoria 3101,

Australia

Email:ipaj-ed@unimelb.edu.au

$\mathrm{Tel}+61398160485$

Fax +61398160477

\section{For business matters}

Ms. Susan M. Oster

Managing Editor, International Psychogeriatrics

International Psychogeriatric Association

550 Frontage Road,

Suite 3759

Northfield, IL 60093

USA

Email:ipa@ipa-online.org

Tel: +1 8475013310

Fax: +1 8475013317

Web: www.ipa-online.org

\section{For book review matters:}

Dr. Michael Philpot

Maudsley Hospital,

Mental Health of Older Adults Directorate

115 Denmark Hill,

London SE5 8AZ

U.K.

Email:

mike.philpot@slam.nhs.uk

Tel: +44 (0) 2072192193

Fax: +44 (0) 2079192118

Enquiries about advertising should be sent to the Journal's Promotion Department of the Cambridge or American Branch of Cambridge University Press. 


\title{
International Psychogeriatrics
}

\section{CONTENTS}

\author{
Guest Editorial 211 Combating ageism \\ Robert N. Butler (U.S.A.)
}

For Debate 212 Dementia with Lewy bodies and Parkinson's disease dementia: are they the same entity?

John O'Brien (U.K.), G. J. Revuelta and C. F. Lippa (U.S.A.), Dag Aarsland (Norway), E. Londos (Sweden), Clive Ballard, Ian McKeith (U.K.)

Reviews

225 Psychosocial treatments of behavior symptoms in dementia: a systematic review of reports meeting quality standards Daniel W. O'Connor, David Ames, Betina Gardner and Madeleine King (Australia)

241 Psychosocial treatments of psychological symptoms in dementia: a systematic review of reports meeting quality standards Daniel W. O'Connor, David Ames, Betina Gardner and Madeleine King (Australia)

252 Small, homelike care environments for older people with dementia: a literature review

Hilde Verbeek, Erik van Rossum, Sandra M. G. Zwakhalen, Gertrudis I. J. M. Kempen and Jan P. H. Hamers (The Netherlands)

Top cited paper

265 Top cited papers in international psychogeriatrics: 2. quality adjusted life years in older adults with depressive symptoms and chronic medical disorders

Jürgen Unützer (U.S.A.), David Ames (Australia)

Original Research 268 Dutch psychogeriatric day-care centers: a qualitative study of the needs and wishes of carers

Articles Jeltsje D. de Jong and F. Boersma (The Netherlands)

278 A psychiatric intensive care unit for older adults: an interval comparison of admissions Gary S. Stevenson, Muhammad A. Khan and Nagarajan Perumal (Scotland)

286 Psychotropic medication use and cognition in institutionalized older adults with mild to moderate dementia Laura H. P. Eggermont, Kerst de Vries and Erik J. A. Scherder (The Netherlands.)

295 Training in dementia care: a cluster-randomized controlled trial of a training program for nursing home staff in Germany Bettina Kuske, Tobias Luck, Stephanie Hanns, Herbert Matschinger, Matthias C. Angermeyer, Johann Behrens and Steffi C. Riedel-Heller (Germany.)

309 What would help me stop abusing? The family carer's perspective Amber Selwood, Claudia Cooper, Colm Owens, Martin Blanchard and Gill Livingston (U.K.)

314 Caregiver factors contributing to psychological elder abuse behavior in long-term care facilities: a structural equation model approach Jing-Jy Wang, Mei-Feng Lin (R.O.C.), Hung-Fu Tseng (U.S.A.) and Wen-Yun Chang (R.O.C.)

321 Evaluations of end of life with dementia by families in Dutch and U.S. nursing homes

Jenny T. van der Steen, Marie-José H. E. Gijsberts Martien T. Muller (The Netherlands), Luc Deliens (The Netherlands and Belgium) and Ladislav Volicer (Czech Republic)

330 Late life depression and dementia: a mental health literacy survey of Australian general practitioners Chanaka Wijeratne and Peter Harris (Australia)

338 The utility of the Mini-mental State Examination in guiding assessment of capacity to consent to research Paul J. P. Whelan, Justyna Oleszek, Alastair Macdonald and Fiona Gaughran (U.K.)

345 Reliability and validity of the telephone version of the Cantonese Mini-mental State Examination (T-CMMSE) when used with elderly patients with and without dementia in Hong Kong Shui Sang Wong and Kenneth Nai Kuen Fong (Hong Kong)

354 Lack of association of neprilysin gene polymorphisms with Alzheimer's disease in a southern Chinese community Yan Fu, Ai Feng Li (China), Jia Jun Shi (U.S.A.), Mou Ni Tang, Yang Bo Guo and Zhen Huan Zhao (China)

359 Vascular risk factors and cognitive function among 3763 participants in the Hypertension in the Very Elderly Trial (HYVET): a cross-sectional analysis

Ruth Peters, Nigel Beckett (U.K.), Françoise Forette (France), Jaakko Tuomilehto (Finland), Craig Ritchie, Ivan Walton, Adam Waldman, Robert Clarke, Ruth Poulter, Astrid Fletcher and Christopher Bulpitt (U.K.)

369 Depression in the elderly in Vellore, South India: the use of a two-question screen S. S. Biswas, R. Gupta, H. A. Vanjare, S. Bose, J. A. Patel, S. Selvarajan, J. Aaron, E. Nitya, D. S. Iyer, N. S. M. Jacob, K. R. John and K. S. Jacob (India)

372 Nature, prevalence and factors associated with depression among the elderly in a rural south Indian community A. P. Rajkumar, P. Thangadurai, P. Senthilkumar, K. Gayathri (India), M. Prince (U.K.) and K. S. Jacob (India)

379 The relationship between population growth and elderly suicide rates: a cross-national study Ajit Shah (U.K.)

384 Correlates of lifetime alcohol misuse among older community residents in Brazil Sergio Luís Blay (Brazil), Gerda G. Fillenbaum (U.S.A.), Sergio Baxter Andreoli1 and Fábio Leite Gastal (Brazil)

392 Characteristics and diagnostic profile of patients seeking dementia care in a memory clinic in Hong Kong Bun Sheng, Chun Bon Law and Kwan Mo Yeung (Hong Kong and Republic of China)

401 Places, social relations and activities in the everyday lives of older adults with psychiatric disabilities: an interview study M. Nordström, A. Dunér E. Olin and H. Wijk (Sweden)

Letters

Book Review

Thanks to

International

Psychogeriatrics

reviewers 